\title{
DISCURSOS SOBRE LITERATURA: RELAÇÕES ENTRE CÂNONE E GÊNERO TEXTUAL
}

\author{
Mateus Robaski Timm \\ Mestrando em Teoria da Literatura pela PUCRS, bolsista CNPq \\ mateustimm@outlook.com
}

\begin{abstract}
RESUMO
Este artigo busca relacionar textos que sistematizaram muitos autores de literatura em relativamente pouco espaço textual. Os períodos abordados são a incipiente historiografia da literatura brasileira, a década de 1950 com os estudos sobre prosa de ficção e o debate contemporâneo acerca da literatura brasileira. Nos textos analisados foi feita uma busca por aproximações ou distanciamentos das estratégias utilizadas na configuração de discursos que trabalham com um corpus de autores e de obras. A reflexão sobre os tipos de apresentação discursiva para a literatura ambiciona mostrar como um gênero textual conduz a um corpus de escritores adequados à sua proposta teórica.
\end{abstract}

Palavras-chave: cânone literário, gêneros do discurso, historiografia da literatura brasileira.

RÉSUMÉ
Cet article cherche à établir des rapports entre des textes qui ont fait une systématisation de plusieurs auteurs de littérature dans peu d'espace textuel. Les périodes abordées sont la naissante historiographie de la littérature brésilienne, la décennie de 1950 avec des études sur la prose de fiction et le débat contemporain sur la littérature brésilienne. Une recherche a été faite dans les textes analysés pour découvrir des approximations ou des éloignements dans les stratégies utilisées pour configurer des textes qui ont travaillé avec un corpus d'auteurs et d'oeuvres. La réflexion sur les types de présentation discursive pour la littérature ambitionne montrer comment un genre textuel conduit à un corpus d'écrivains adéquat au propos théorique.

Mots-clés: canon littéraire, genres du discours, historiographie de la littérature brésilienne.

\section{INTRODUÇÃO}

O discurso pode assumir diversas formas para explicar a literatura. Agora, se o objetivo for estabelecer reflexões sobre muitos escritores dentro de um relativamente curto espaço textual, os gêneros discursivos serão mais restritos. A leitura e o cotejo deste tipo de 
organização enunciativa proporciona constatar uma tessitura ontológica de itens configurativos nestes textos. Tais componentes essenciais acabam entrando em contato com preocupações epistemológicas historicizáveis, itens que também contribuem para a composição dos discursos sobre literatura.

No texto intitulado "Os gêneros do discurso", Mikhail Bakhtin evidencia a relação intrínseca entre as formas de uso da linguagem e os campos da atividade humana, fatores para a criação dos gêneros do discurso, enunciados relativamente estáveis, reconhecíveis dentro de uma comunidade linguística. Para Bakhtin, os gêneros do discurso refletem as condições particulares e os objetivos "de cada referido campo não só por seu conteúdo (temático) e pelo estilo da linguagem, ou seja, pela seleção de recursos lexicais, fraseológicos e gramaticais da língua, mas, acima de tudo por sua construção composicional" (BAKHTIN, 2011, p. 261).

Ao longo do tempo, os estudos sobre a literatura brasileira foram publicados sob muitos nomes: parnaso, bosquejo, florilégio, panorama, mapeamento, história, formação, entre outros. Os enunciados que sistematizam a literatura se modificam porque o seu campo de estudo se desenvolve e se complexifica. Logo, valer-se de um gênero discursivo gera uma carga semântica que faz o leitor ativar uma expectativa pelo conteúdo e sua organização textual.

O uso de certas construções discursivas com o objetivo de sistematizar um grupo de autores está associado à concepção que determinado gênero textual possui uma estrutura eficaz para esta intenção enunciativa. Os vários gêneros do discurso praticados para a apresentação de um corpus de escritores mostra como as sistematizações são elaboradas com diferentes finalidades. Assim, este artigo expõe e relaciona textos teóricos, de três 
momentos distintos, que trabalharam na sua configuração discursiva com autores e obras: na incipiente historiografia literária do século XIX, nos debates sobre prosa de ficção da década de 1950 e nas discussões sobre literatura brasileira contemporânea no século XXI.

\section{A HISTORIOGRAFIA LITERÁRIA ROMÂNTICA}

As primeiras configurações discursivas, propondo uma seleção de autores de literatura, assumiram, no século XIX, a forma de parnasos e florilégios, em consonância com a necessidade de legitimação da qualidade literária brasileira, em oposição à produção portuguesa.

No contexto brasileiro posterior a 1822, torna-se compreensível por que os críticos nacionais, sacudidos pelos ideais românticos, tenham tomado a si a missão de fomentar o debate em torno da existência e constituição da literatura. Tratava-se, então, de encontrar mecanismos capazes de legitimar a recém implantada nação, e a literatura oferecia-se como uma boa alternativa para a consecução desse objetivo. Declarar a diferenciação da literatura produzida no Brasil em relação à produção poética da exmetrópole foi a fórmula encontrada pelos intelectuais do país para contribuir com a tarefa de consolidação política da nação (ZILBERMAN; MOREIRA, 1998, p. 9).

Esta lógica mostra que a configuração de um discurso sobre literatura é um mecanismo participando dos jogos de poder, a serviço da consolidação de determinadas propostas. Neste caso, a incipiente historiografia literária contribuía para a estabilidade política da recém constituída nação.

O Parnaso brasileiro (1829-1832) de Januário da Cunha Barbosa foi uma proposta pioneira, vinda de alguém nascido do lado de cá do Atlântico, de uma seleção de autores brasileiros, visando a sua divulgação junto ao público. Como dito no seu subtítulo, o Parnaso 
brasileiro almejou oferecer uma "coleção das melhores poesias dos melhores autores do Brasil, tanto inéditas como já impressas". Januário da Cunha Barbosa aponta que empreendeu uma coleção "das melhores poesias dos nossos poetas, com o fim de tornar ainda mais conhecido no mundo literário o gênio daqueles brasileiros, que, ou podem servir de modelos, ou de estímulo à nossa briosa mocidade, que já começa a trilhar a estrada das belas letras" (Ibid., p. 84). A sua seleção buscava a preservação da memória literária, pois "tantas poesias estimáveis que o tempo já vai consumindo", corriam o risco de desaparecer.

A configuração textual do Parnaso brasileiro é simples, consistindo na disposição em sequência de poesias junto com alguma informação biográfica. O gênero discursivo parnaso literário necessita apenas da exposição de poemas, mas Januário da Cunha Barbosa fez mais: escreveu um curto prólogo e uma pequena apresentação, ou seja, um singelo esforço de síntese do heterogênio e, ao mesmo tempo, uma marca histórica pela sua posição exordial.

O trabalho narrativo, valendo-se de autores e obras, para formalizar determinadas concepções sobre literatura, tem por precursor nacional Joaquim Norberto de Sousa Silva. O "Bosquejo da história da poesia brasileira" (1840), texto que precede as Modulações poéticas (poesia do próprio autor), funda o gênero no Brasil. O bosquejo literário é um gênero discursivo usufruindo da semântica de um termo das artes plásticas. Nesta área, "bosquejo" é um trabalho preparatório que serve de primeiro passo para a concepção de uma obra maior. Transposta tal ideia para um discurso sobre literatura, ela possibilita esboçar grupos de autores, a partir de traços característicos em comum. Joaquim Norberto operou este compartilhamento seletivo, enquanto procedimento construtivo do seu discurso, dividindo os autores em "épocas". Entrementes, a separação dos autores em seis 
compartimentos temporais tenciona diferenciar a "sexta época", na qual a literatura brasileira satisfez as expectativas românticas:

Ferdinand Denis tinha predito - que o Brasil, que sentira a necessidade de adotar instituições diferentes das que lhe impusera a Europa, - que o Brasil conhecia também a necessidade de ir beber sua inspirações poéticas à fonte que verdadeiramente Ihe pertence; - dentro em pouco tempo as primorosas obras desse primeiro entusiasmo que atesta a galhardia e mocidade de qualquer povo; - sim a profecia cumpria-se e essa época de glória literária vem raiando!

Um jovem nascido sobre o picturesco solo do Rio de Janeiro, abrasado nas chamas da poesia, ávido de nome, ardente de glória, nutrido em sua infância com a leitura dos poetas [...]. [E]xpôs-se, ergueu o estandarte da reforma, pôs-se a frente da mocidade e uma nova época começou para a poesia brasileira. Louvores ao jovem fluminense! Louvores a[o] Sr. Dr. D. J. G. de Magalhães! (SILVA, 1997, p. 64).

Ao por em evidência a primeira geração romântica, e chamar ao proscênio Gonçalves de Magalhães, Joaquim Norberto estabeleceu uma escolha convergente ao projeto de formação de uma identidade nacional. A sua colaboração se realizou através de um discurso pertinente para a divulgação da literatura brasileira, num momento em que "uma indiferença de morte pesa[va] sobre a literatura nacional, e com desprezo se olha[va] para os literatos" (ZILBERMAN; MOREIRA, 1998, p. 95). Os autores presentes na "sexta época" foram eleitos por Joaquim Norberto, o que gerou "tanta injusta crítica, tanto sarcasmo por havermos eliminado de nossas páginas centenas de contemporâneos, poetas da dileção de nossos detratores" (Ibid., p. 99). A tensão de opiniões sobre a inclusão de determinados escritores é uma consequência típica de toda construção discursiva que trabalha com um corpus de autores vivos. O intuito do texto, "esboçar essas fases, a que chamamos épocas", ocorreu mediante uma seleção de autores, ação essencial para este tipo de gênero que 
busca sistematizar muito do fenômeno literário, num pequeno espaço textual. Os méritos do "Bosquejo" são incontestáveis para a historiografia da literatura brasileira, afinal Joaquim Norberto:

Visa recuperar o "quadro da história da nossa literatura dos nossos passados anos", (...) "apontando os representantes das diversas fases, que oferece a história de nossa poesia", atendendo ao plano "de escrever uma obra do mesmo gênero, porém muito mais extensa". Nele, [Joaquim Norberto] delineia um panorama da cultura portuguesa e das condições na América, como divide a literatura brasileira em seis épocas (MOREIRA, 2004, p. 129).

Estas considerações fornecem características do gênero bosquejo literário: estabelecer um quadro de um dado período, apontar autores representativos para cada subdivisão periodológica, e ser feito à semelhança de um plano, podendo surgir deste esboço uma obra mais desenvolvida.

Outro gênero discursivo praticado pela incipiente historiografia da literatura brasileira foi o florilégio literário. Francisco Adolfo Varnhagen é, no país, no século XIX, o representante mais significativo do gênero. O Florilégio da poesia brasileira (1850) apresenta como introdução o "Ensaio histórico sobre as Letras no Brasil", seguido de poemas de diversos autores. Esta fusão de elementos composicionais (uma introdução e a seleção de poemas) mostra o desenvolvimento dos gêneros do discurso que procuram dar conta da sistematização de autores. Por conseguinte, é possível constatar que além da escolha de um corpus de escritores, tornara-se de bom gosto a escrita de um texto introdutório sobre a literatura brasileira.

O Florilégio da poesia brasileira tem a peculiaridade restritiva de ser uma "coleção das mais notáveis composições dos poetas brasileiros falecidos". Talvez por evitar uma 
construção textual sediciosa, os dois primeiros volumes do florilégio tenham recebido a "boa acolhida" que o autor alude no terceiro tomo. Quanto à finalidade da formação de um cânone, Varnhagen explicita que pretendia inserir autores brasileiros no contexto europeu:

vista a impossibilidade, e quase inutilidade de publicar tudo, resolvemos dar à imprensa o que nos pareceu mais a propósito. [...] Como o entusiasmo que temos pela América, onde vimos a luz, e a fé no desenvolvimento futuro da poesia, era um dos nossos estímulos, julgamos dever dar preferência a esta ou àquela composição mais limada, porém semigrega, outra embora mais tosca, mas brasileira, ao menos no assunto. Esta decisão nos facilitou a empresa, e cremos que esta coleção adquirirá com isso mais interesse para o leitor europeu, ao passo que deve lisonjear o americano (ZILBERMAN; MOREIRA, 1998, p. 224).

Oferecer uma amostragem da poesia brasileira, privilegiando os poemas de conteúdo "americano" está de acordo com a modulação semântica do título, como diz o próprio Varnhagen, "não chamamos Parnaso a esta coleção, pelo mesmo motivo de estarmos um pouco em briga com a mitologia" (Ibid., p. 225). Na construção de uma identidade romântica para a literatura brasileira, os discursos sobre um corpus de autores acabam pondo em evidência os poemas que estão de acordo com a sua concepção de literatura.

Januário da Cunha Barbosa, Joaquim Norberto de Sousa Silva e Francisco Adolfo de Varnhagen escreveram textos significativos para um primeiro cânone brasileiro. Nos seus textos, as obras que foram privilegiadas estavam adequadas a uma concepção de identidade nacional, afirmando a sua especificidade em oposição à literatura de Portugal.

\section{DEBATES SOBRE PROSA DE FICÇÃO NA DÉCADA DE 50}

No século XX, os estudos sobre literatura voltaram-se com ímpeto para a discussão sobre a prosa de ficção. Atrelada a isto, está a necessidade de configurar novos cânones, 
posicionando autores e obras em sistemas plausíveis. Nos textos da década de 50, os discursos sobre diferenciação de correntes e escolas literárias já alcança certo grau de sofisticação reflexiva, garantido pelo amadurecimento do seu aspecto narrativo. Por sua vez, o estudo de autores é um gênero discursivo amplamente usado para a pormenorização de um cânone. Enquanto que a sistematização narrativa de um grupo de escritores em textos introdutórios continuou como forma frequente de enunciado sobre a literatura brasileira.

No ano de 1950 é lançado Prosa de Ficção (1870 a 1920), primeira grande sistematização no Brasil dos gêneros romance, conto e novela. Lúcia Miguel Pereira arquitetou o seu trabalho, partindo de uma introdução, para em seguida elencar o estudo interpretativo de vinte e três autores de ficção brasileira, agrupados em tendência pela semelhança de traços estilísticos. A "Introdução" mostra-se importante para o reconhecimento dos autores que Lúcia Miguel Pereira considera relevantes nas letras brasileiras. Este procedimento seletivo contribuiu na manutenção da memória da literatura, visto que Lúcia Miguel Pereira foi referência para outros trabalhos sobre o romance brasileiro. Consciente de estar escrevendo história literária, a autora diz ficar entre a crítica e a história social, quando procura sistematizar a ficção. Ela parte do princípio que quando a história literária está

Adstrita a levar em consideração elementos estranhos ao conteúdo artístico - e neste se incluem tanto o sentido estético quanto o ético - corre [...] o risco de dar apreço excessivo a livros que só valem como documentos, pelas informações que encerram, e a se desviar do seu fim: estudar os sucessos literários, isto é, as obras que por si mesmas ou pela repercussão que tiveram, significam alguma coisa. Fica assim entre a crítica, que the permite a avaliação, e a história social, que a ajuda a discriminar as relações entre a vida e a literatura [...]. Não será essa a posição ideal, mas é 
a única possível na nossa situação, já que, se poucos escritores de grande mérito possuímos, muitos temos a exigir atenção pelas tendências que refletem (PEREIRA, 1957, p. 14).

Neste trecho, a autora desvela a sua postura metodológica e o seu critério para a seleção de autores e obras: a história literária deve refletir sobre os "sucessos literários", obras que tiveram boa repercussão ou que refletiram eficazmente certas tendências. Estas considerações e o recorte temporal (1870-1920) possibilita que Lúcia Miguel Pereira eleja Machado de Assis como autor central deste momento de intensificação da escrita em prosa ficcional. Assim, Machado de Assis é "o maior dos romancistas brasileiros, [...] o único que pode sofrer o paralelo com os grandes vultos universais [...]; a todos os outros, inclusive a Raul Pompéia e Lima Barreto [...], é indispensável o socorro do relativismo histórico" (Ibid., p. 15). O posicionamento da autora fica evidente neste curto trecho, elegendo Machado de Assis como maior expoente nacional no gênero romance, e posicionando, nos painéis laterais de um tríptico, Raul Pompéia e Lima Barreto. Em outra passagem, Lúcia Miguel Pereira reforça a proeminência do autor de Memórias Póstumas de Brás Cubas, estabelecendo um contraste entre Machado e os outros "valores de nossa literatura":

Esta síntese, que não poderia escapar a todos os perigos das generalizações, visa apenas apontar a causa - ou uma das causas - da pobreza de nossa ficção num época que foi, entretanto, muito fértil quantitativamente e que, mesmo qualitativamente, produziu alguns dos valores da nossa literatura, para não falar no maior de todos - Machado de Assis. A explicação poderá parecer desnecessária, visto como não se pode esperar de um povo jovem grande riqueza literária, acrescendo que as nossas condições deveriam ser idênticas às de todos os países colonizados (Ibid., p. 20).

Portanto, a "Introdução" foi configurada narrativamente para dar uma posição central a Machado de Assis. Tal posicionamento ampara-se no emprego de citações, usadas 
enquanto reforço para a legitimação da sua proposta. Desta maneira, E. M. Forster, François Mauriac, T. S. Eliot são integrados textualmente por fornecerem subsídios à perspectiva da autora, que visa estabelecer um sistema com os prosadores brasileiros. É por construções tão bem armadas discursivamente, como Prosa de Ficção, que determinados autores sobrevivem na memória coletiva dos leitores.

Uma conferência realizada na Academia Brasileira de Letras também optou pela tarefa de sistematizar um grande número de autores e obras. Trata-se do "Panorama do romance brasileiro", de Menotti Del Picchia. O termo panorama vem impregnado do sentido referente às áreas da pintura e da fotografia: um panorama costuma prover uma visão ampla, abarcando o máximo de espaço possível num suporte muito menor. Destarte, o "Panorama do romance brasileiro" disserta sobre muitos autores e obras, distribuindo-os num curto espaço textual. O maior número de teóricos chamados para contribuir no discurso sobre determinado escritor colabora para evidenciar a sua importância num dado sistema literário. Assim, no texto de Del Picchia, José de Alencar e Machado de Assis são postos em evidência, através do maior espaço textual dedicado a estes autores, e pelo bom número de especialistas chamados para acrescentar no debate sobre eles.

Antes de desenvolver o seu panorama de autores e esboçar as correntes a que pertencem, Del Picchia precisou assegurar à sua exposição uma clara definição do gênero romance. Para esta tarefa, traz a contribuição de E. M. Forster, Gide, Casais Monteiro, enquanto percurso reflexivo para, então, propor a concepção que orientará o seu panorama: "o romance, no seu conceito atual, passou a ser a uma recriação ideal da vida pela narração de episódios reais ou fabulosos, associados por um espírito de unidade o qual é no fundo o ponto nuclear do gênero" (PICCHIA, 1952, p. 12). A definição do objeto do discurso tem se 
mostrado procedimento frequente nos textos que trabalham com um grande número de autores, pois tal especificação delimita o corpus: as obras que não se enquadrarem à proposta estabelecida serão desconsideradas da composição textual.

Outro trabalho, da década de 50, sobre prosa de ficção foi realizado por Eugênio Gomes que, semelhante à Prosa de ficção, construiu uma exposição de estudos sobre prosadores, embora sem escrever uma introdução de fôlego. Os estudos de autor que compõem o livro Aspectos do romance brasileiro (1958) possuem um viés analítico próprio para a formação de um cânone:

Ante a complexidade do tema, decidi-me pelo ângulo que julgo pouco explorado em nosso país: o da ficção vista como uma obra de arte mais ou menos autônoma. Para este efeito, tive de restringir-me à área da literatura mais adaptável a um estudo crítico desta natureza, atento à circunstância de que, por força da reação modernista, o gênero desprendeu-se progressivamente do imperativo formal, encaminhando-se para outras direções (GOMES, 1958, p. 6).

Esta metodologia permitiu a Eugênio Gomes eleger um autor como representante fulcral de cada corrente estética. Desta maneira foram emparelhados "o romantismo com José de Alencar; o romance picaresco ou de costumes, com Manuel Antônio de Almeida; o realismo psicológico e estético, com Machado de Assis; o naturalismo, com Aluízio Azevedo" (Ibid., p. 7). Unir um escritor a um momento estético é outra estratégia para por em evidência determinados autores, contribuindo para o debate sobre quais leituras devem ser feitas a priori por uma comunidade de leitores. Também nesta diretriz, Machado de Assis é posto no topo da hierarquia, pois a "estética do romance atingiu, com Machado de Assis, o mais alto grau de refinamento formal" (Ibid., p. 77). 
As abordagens que efetuam uma síntese do heterogêneo de autores e obras literárias continuaram sendo gêneros do discurso relevantes nas discussões sobre literatura brasileira na década de 50. Os trabalhos de Lúcia Miguel Pereira, Menotti Del Picchia e Eugênio Gomes aparecem como renovadores da tradição de textos que buscam explicar muita literatura, dentro de pouco espaço discursivo. Os estudos citados deram conta de formular sistemas plausíveis, explicativos da prosa de ficção, num momento em que o romance ascendia no cenário das letras brasileiras.

\section{DISCURSOS SOBRE LITERATURA NO SÉCULO XXI}

As estratégias discursivas que configuram em sistema a literatura brasileira contemporânea receberam a herança de procedimentos narrativos, porém assumindo configurações particulares. Com a renovação dos estudos sobre literatura, novas questões apareceram relacionadas à construção de um cânone literário, instigando a quem busca sistematizar um grupo de autores e obras a não sentir segurança em seleções estáveis, já operadas. Esta postura teórica leva Susana Scramim a apontar que

Pensar a literatura na sua experiência sem a garantia de um caminho seguro já trilhado é assumi-la em sua vida interior, sua vida a meio do caminho, que "ainda-não-se-realizou" na sua realização, vida esta composta por formas originárias que se caracterizam por serem a soleira da potência do mundo empírico da literatura frente à sua correlação entre outras tantas formas de vida interior (SCRAMIM, 2007, p. 32).

A consciência que os discursos sobre literatura possuem a potencialidade de interagir com o mundo empírico trouxe o peso da ética para a questão da formulação de grupos representativos de autores. Em decorrência disto, as produções discursivas contemporâneas assumem cada vez mais a incompletude como qualidade ontológica para a formação de um novo corpus. Assim, Karl Erik Schøllhammer abre o seu Ficção brasileira contemporânea: 
"Este livro não pretende esgotar o tema da "ficção contemporânea", nem se propõe a ser uma introdução à ficção brasileira que aborde todos os seus aspectos e todos os autores relevantes surgidos nas últimas décadas" (SCHØLLHAMMER, 2009, p. 7). Entretanto, a incompletude não pode ser confundida com falta de seleção, pois o discurso de Schøllhammer privilegia alguns autores na construção textual. Exemplo disto é a maciça presença de Rubem Fonseca, utilizado como expoente de diversas vertentes literárias: brutalismo, metaficção historiográfica, hibridismo e conto curto.

O "Breve mapeamento das últimas gerações", primeiro capítulo de Ficção brasileira contemporânea aciona a semântica da cartografia, com a representação em escala reduzida da superfície total ou parcial de um território. Trabalhar em termos de reconhecimento do terreno permite igualmente uma abordagem eficaz dos fenômenos literários. Sobre a sua opção por um mapeamento literário, Schøllhammer diz que tal escolha:

não é guiada pela preocupação de caracterizar uma geração, mas procurará trazer para a discussão um repertório de escritores e de obras que iluminam cortes e continuidades na ficção brasileira, possibilitando mapear temas e opções estilísticas e formais que se apresentam na escrita dos autores contemporâneos. Evidentemente, as escolhas não serão determinadas pelos valores de que se vale o mercado literário, pelas estatísticas de venda ou prêmios, ainda que estes representem mecanismos eficazes de canonização e de marketing (Ibid., p. 21).

O mapeamento literário é um gênero novo, e esta descrição feita por Schøllhammer ajuda a compor o seu repertório de elementos composicionais: 1) a eleição de um cânone, que melhor evidencie "cortes e continuidades na ficção brasileira"; 2) o desdobramento da pesquisa com o intuito de encontrar tessituras compartilhadas de "temas e opções estilísticas e formais"; 3) o mercado como elemento a ser considerado, já que a seleção gera 
visibilidade; 4) o reconhecimento do caráter legitimador das estatísticas de venda e dos prêmios.

Outra potencialidade dos livros que abordam a literatura contemporânea é serem organizações de textos de autores diversos, sobre temas, escritores e livros também heterogêneos. Exemplo de coletânea de ensaios é Alguma prosa - ensaios sobre literatura brasileira contemporânea. Este livro apresenta um caráter seletivo em dois graus: primeiro, os organizadores do livro tiveram de escolher ensaístas para este trabalho; segundo, do lado destes últimos, houve a seleção do escritor escolhido para estudo. Os autores dos textos forneceram uma amostra da multiplicidade de autores e obras da atual literatura brasileira, evidência que leva a proposta de abdicação de um cânone central e inquestionável. Renato Cordeiro Gomes explica a estratégia do livro:

o caráter seletivo, com o propósito de abdicar da tentação de totalidade, está justamente expresso justamente no "alguma" do título. [Alguma prosa não pretende] oferecer um panorama completo da literatura brasileira contemporânea. Os ensaios são eles próprios recortes, são "alguma prosa" desses professores que circulam pela universidade, que olham detidamente alguns autores, alguns textos produzidos no Brasil a partir da década de 80 (GOMES, 2007, p. 9).

Esta apresentação é representativa de novas ações dos estudos sobre literatura: a certeza do aspecto incompleto, a presença de professores universitários legitimando a qualidade dos livros e a opção pelo enfoque em autores dos últimos quarentas anos de produção literária. Pela diversidade de escritores disponíveis para compor um corpus,

A tentativa de esboçar os contornos de nossa literatura atual está atrelada a questões como o papel ou o lugar da história literária junto aos pesquisadores; o modo, o campo, os limites adequados para a seleção dos dados; as bases para o agrupamento dos produtores e produtos em escolas, 
estéticas, movimento e similares. A tais questões agrega-se, naturalmente, [a seguinte indagação]: como inscrever, na história contemporânea, a narrativa literária que se publica à nossa volta? (PEREIRA, 2011, p. 33).

Por isto, os autores de textos que trabalham com a memória relativa à literatura precisam levar em conta o fato de que produzem um conhecimento em detrimento de outro, havendo na sistematização a responsabilidade de escolher quem aparecerá no discurso e quem ficará silenciado. A inscrição na história contemporânea passa pela necessidade de revitalização do corpus de autores canônicos. Tal procedimento mostra-se de maior eficácia quando procede pelo método da inclusão, mesmo sabendo que determinada seleção não perdure, como bem aponta Ettore Finazzi-Agrò:

Trabalhar com a literatura brasileira de hoje - ou apenas de ontem -, tentar traçar um panorama e fazer um balanço da produção literária dos nossos dias é tarefa difícil [...], sabendo de antemão que essa "pontualidade" com um discurso poético tão heterogêneo e tão disperso, no momento de se fazer momentaneamente perfeito, não prevê nenhuma garantia. Mesmo assim, perscrutar o presente é preciso para chegar a entender aquilo que, acontecendo hoje, ecoa no passado e no futuro - e inevitavelmente os transforma, deixando que o sentido se cristalize num sentido anacrônico e intempestivo (FINAZZI-AGRÒ, 2014, p. 7).

As formas de discurso sobre literatura contemporânea passaram a perceber a canonização como um empreendimento instável. Esta visão do fenômeno literário encontrase relacionada com a consciência da incompletude de qualquer trabalho que busque sistematizar um grupo de autores e obras. Uma solução para expor a diversidade de produções contemporâneas é a organização de ensaios sobre autores, numa não concatenação narrativa. Além disso, categorias como o mercado, os índices de venda e as premiações são instâncias hoje incontornáveis para trabalhos com um grande número de autores. 


\section{CONCLUSÃO}

Ao passar por tantas formas de explicar a literatura foi possível compreender melhor o emprego de terminologias específicas na construção dos gêneros discursivos que visam fazer a síntese de um heterogêneo de autores. Esta seleção de elementos composicionais diz respeito a um posicionamento, em face à necessidade de escrever sobre literatura que, enquanto objeto de estudo, possui historicamente as mais diversas abordagens, acumuladas numa tradição viva, em constante transformação. Logo, as escolhas composicionais para construir um discurso sobre literatura valem-se da semântica dos gêneros: em comparação aos amenos bosquejos e florilégios, temos, hoje, o mapeamento, com uma ativação de sentido muito mais arrojada, procurando dar conta da heterogeneidade contemporânea. A reflexão sobre a montagem do discurso abarcando diversas obras é importante para se perceber as conformações que a literatura encontra quando em contato com diferentes finalidades.

\section{REFERÊNCIAS}

BAKHTIN, Mikhail. Estética da criação verbal. São Paulo: Editora WMF Martins Fontes, 2011. FINAZZI-AGRÒ, Ettore. "Apresentação". In: REZENDE, Beatriz, FINAZZI-AGRÒ, Ettore (Orgs.). Possibilidades da nova escrita literária no Brasil. Rio de Janeiro: Revan, 2014.

GOMES, Eugênio. Aspectos do romance brasileiro. Editora progresso, 1958.

GOMES, Renato Cordeiro. "Duas ou três coisas que eu sei sobre ela". In: DEALTRY, Giovanna. Alguma prosa - ensaios sobre literatura brasileira contemporânea. Rio de Janeiro: 7 Letras, 2007.

MOREIRA, Maria Eunice. "Na rede do tempo. História da literatura e fontes primárias - a contribuição de Joaquim Norberto". In: ZILBERMAN, Regina et alii. As pedras e o arco. Fontes primárias, teoria e história da literatura. Belo Horizonte: Editora UFMG, 2004.

PEREIRA, Helena Bonito. Novas leituras da ficção brasileira no século XXI. São Paulo: Universidade Presbiteriana Mackenzie, 2011. 
PEREIRA, Lúcia Miguel. Prosa de Fiç̧ão (De 1870 a 1920). Rio de Janeiro: José Olympio, 1957. PICCHIA, Menotti Del. "Panorama do romance brasileiro". In: Curso de romance. Conferências realizadas na Academia Brasileira de Letras. Rio de Janeiro: Academia Brasileira de Letras, 1952.

SCHØLLHAMMER, Karl Erik. Ficção brasileira contemporânea. Rio de Janeiro: Civilização Brasileira, 2009.

SCRAMIM, Susana. Literatura do presente: história e anacronismo de textos. Chapecó: Argos, 2007.

SILVA, Joaquim Norberto de Sousa. Bosquejo da história da poesia brasileira. Belo Horizonte: Editora UFMG, 1997.

ZILBERMAN, Regina, MOREIRA, Maria Eunice (Orgs.). O berço do cânone. Porto Alegre: Mercado Aberto, 1998.

Artigo recebido em: 31 de maio de 2018. Artigo aprovado em: 21 de agosto de 2018. 